\title{
CHAOS CONTROL AND SYNCHRONIZATION USING SYNERGETIC CONTROLLER WITH FRACTIONAL AND LINEAR EXTENDED MANIFOLD
}

\author{
Morteza Pourmehdi, Abolfazl RanJbar Noei*, AND Jalil SADATi \\ Department of Electrical \& Computer Engineering, \\ Babol University of Technology, Babol, Iran. \\ morteza.pourmehdi1366@gmail.com; *a.ranjbar@nit.ac.ir; and j.sadati@nit.ac.ir \\ (Received: 02 Jun. 2015; Accepted: 20 Sept. 2015; Published on-line: 30 Apr. 2016)
}

\begin{abstract}
In this manuscript, for the first time, a fractional-order manifold in a synergetic approach using a fractional order controller is introduced. Furtheremore, in the synergetic theory a macro variable is expended into a linear combination of state variables. An aim is to increase the convergence rate as well as time response of the whole closed loop system. Quality of the proposed controller is investigated to control and synchronize a nonlinear chaotic Coullet system in comparison with an integer order manifold synergetic controller. The stability of the proposed controller is proven using the Lyapunov method. In this regard stabilizing control effort is yielded. Simulation result confirm convergence of states towards zero. This is achieved through a control effort with fewer oscillations and lower amplitude of signls which confirm feasibility of the control effort in practice.
\end{abstract}

\begin{abstract}
ABSTRAK: Manuskrip ini memperkenalkan, buat kali pertama, manifold pecahan pesanan dalam pendekatan sinergi yang menggunakan pengawal pecahan pesanan. Dalam teori sinergi pembolehubah makro diperluaskan menjadi satu kombinasi linear pembolehubah keadaan. Tujuannya adalah untuk meningkatkan kadar penumpuan serta masa tindak balas keseluruhan sistem lingkaran tertutup. Kualiti pengawal yang dicadangkan dikaji dari segi mengawal dan menyelaras sistem Coullet tak linear berbanding dengan pengawal sinergi pesanan integer manifold. Kestabilan pengawal yang dicadangkan terbukti dengan penggunaan kaedah Lyapunov. Keadaan ini menghasilkan kawalan yang stabil. Simulasi menghasilkan penumpuan keadaan ke arah sifar. Ini dicapai melalui usaha kawalan yang mempunyai kurang pengayunan dan amplitud isyarat lebih rendah dan ini mengesahkan bahawa usaha kawalan dalam amalan boleh dilaksanakan.
\end{abstract}

KEYWORDS: Synergetic control theory; Fractional order system; Synchronization; Nonlinear chaotic Coullet system; Chaos control

\section{INTRODUCTION}

Synergetic control theory is primarily reported by Russian researchers [1]. In essence, a synergetic controller is of an analytical topic with high flexibility in defining dynamical manifold. Fractional order controllers are shown providing quality and robust performance in the presence of uncertainties and disturbances for nonlinear systems [2]. During the design procedure, undesired dynamics can be eliminated by introducing dynamical constraints, defined in a manifold. In this regard specifications of desired performance can be applied to the system according to this manifold. Elimination of undesired dynamics and reduction of the system's order are some issues of desired control specifications. The aim of the synergetic controller is to force states of the system to reach and remain on a manifold 
through macro variables. These variables are selected according to the control goals. When system reaches to the desired manifold, its behavior is usually controlled by a first order differential equation. Innovatively a combination of fractional controller and the synergetic controller is used to improve the tuning process and the convergence of states.

Although synergetic controller is recently proposed, several applications are successfully reported in different fields of engineering. This controller is successfully applied in nonlinear power electronic and industrial processes. Nonlinear power system stabilizers [3],power converters for pulse current charging [4], DC-DC boost converters [5] and control of chaotic oscillation in power systems [6] are such of these applications.

Fractional calculus by over 300 years' history is a generalization of integer order derivative and integral into a real order one. In recent decades, applications of fractional calculus in modeling and control are widely reported. Several works such as [7-16] deals with fractional calculus. Fractional order dynamics are involved in deferent systems such as viscoelasticity materials, electrochemical processes, electrical machines and etc. It is shown in many fields of science and engineering that the fractional operators can provide more accurate modeling[17,18]. During modeling of physical systems which exhibit hereditary, diffusion and viscoelasticity properties [19-22], heat transfer [23], [24], [25], [12] and fractional PID [26] controllers can be mentioned as such examples of applying fractional order controllers in different field. Recently [27] incorporates a combination of synergetic controller with fuzzy theory.

In this manuscript, fractional derivative in the Caputo sense [15] will be utilized. The current research proposes an idea to combine both synergetic controller and fractional operators to control a fractional order chaotic system. This proposed approach shows improving time response and the convergence rate.

The rest of the paper is organized as follows:

In section 2, basics of synergetic theory are introduced. Section 3 briefly describes the Caputo fractional calculus. Synergetic controller with fractional order and together with combined linear extension of the manifold is proposed for the first time in section 4 . The stability of the control system is analyzed in this section. Section 5 investigates with quality of the proposed method through a chaos control of a fractional order system. Synchronization is made possible in section 6 using the proposed fractional-order synergetic structure. Finally, section 7 closes the work by a conclusion.

\section{BASICS OF SYNERGETIC THEORY}

Synergetic method generates a control effort through defining a macro variable introducing required dynamic as a manifold. Assume that the system is represented in the following nonlinear state space equations:

$$
\dot{x}=f(x, u, t)
$$

Where $x$ denotes vector of the state variable, $u$ refers to the vector of the control input, $t$ defines the time variable and finally $f(x, u, t)$ indicates a nonlinear relation between states and input. Synergetic design uses macro variable $\psi(x)$ in either linear or nonlinear function of the state variable such as:

$$
\psi=\psi(x)
$$


Appropriate control law drives states towards and stays on manifold of $\psi(x)=0$. The designer may choose macro variable according to the control specifications and requirements [28]. Macro variables are usually considered as a liner combination of the state variables. Number of macro variables may be defined as much as the control input channels (multi input). A dynamical equation of manifold may be defined as follows [2]:

$$
T \dot{\psi}+\psi=0, \quad T>0
$$

where $T$ denotes the design parameter. This eventually adjusts rate of the convergence of the states in the manifold (2). Equation (3) immediately yields:

$$
\psi(t)=\psi_{0} e^{\frac{-t}{T}}, \quad t \geq 0
$$

The convergence of $\psi(t)$ towards the manifold $\psi(x)=0$ is guaranteed with any bounded initial condition where here the rate of convergence will be tuned by appropriate choice of the design parameter $T$. Roll of parameter $T$ can be found using the following chain rule of Eqn.(4):

$$
\dot{\psi}=\frac{d \psi}{d x} \frac{d x}{d t}=\frac{d \psi}{d x} \dot{x}
$$

Substituting equation Eqn.(5) into Eqn.(3), involving the system Eqn.(1) achieves:

$$
\mathrm{T} \frac{d \psi}{d x} f(\mathrm{x}, \mathrm{u}, \mathrm{t})+\psi=0
$$

Finally, an appropriate control law will be achieved using Eqn.(6) considering other specifications. Each manifold imposes a new constraint to the system which decreases the order of the system.

\section{THE CAPUTO FRACTIONAL DERIVATIVE}

In fractional calculus several methods of Grünwald-Letnikov, Riemann-Liouville and Caputo are commonly used. In this manuscript, the Caputo fractional derivative [15] is used. Benefits of the Caputo technique are studied in [29-32]. This is because initial conditions in the Caputo are of an integer order which is physically realizable. In the Riemann-Liouville definition the initial condition is of a fractional order that is less realizable in practice as well as increases the complexity [15]. The Caputo fractional derivative is defined as follows:

$$
{ }_{0}^{c} D_{t}^{\alpha} f(t)=\frac{1}{\Gamma(n-\alpha)} \int_{0}^{t} \frac{f^{(n)}(T)}{(t-T)^{\alpha-n+1}} d T
$$

where $\Gamma($.$) is the Euler Gamma function. For n-1<\alpha<n$, initial condition of the fractional order differential equation is the same as the integer order one [15]. A unified formula for fractional order integral of $f(t)$ i.e. ${ }_{0}^{c} I_{t}^{\alpha} f(t)$, with $\alpha \in(0,1)$ in sense of the

Caputo in the time interval $[0, \mathrm{t}]$ is defined as follows [15]:

$$
{ }_{0}^{c} I_{t}^{\alpha} f(t)=\frac{1}{\Gamma(\alpha)} \int_{0}^{t}(t-T)^{\alpha-1} f(T) d T
$$


Likewise ${ }_{0}^{c} D_{t}^{\beta} f(t), n-1<\beta<n$ is a Caputo fractional order derivative of $\beta$ as defines as follows [15]:

$$
{ }_{a}^{c} D_{t}^{-\beta}\left({ }_{a}^{c} D_{t}^{\beta} f(t)\right)=f(t)-\sum_{j=0}^{n-1} \frac{f^{(j)}(a)}{j !}(t-a)^{j}
$$

For $a=0, n=0$ and $0 \leq \beta<1$ [15] It is shown that he following relation is yielded:

$$
{ }_{a}^{c} D_{t}^{-\beta}\left({ }_{a}^{c} D_{t}^{\beta} f(t)\right)=f(t)-f(0)
$$

Furthermore, the following relations are also held for the Caputo method [15]:

$$
{ }_{a}^{c} D_{t}^{\alpha}\left({ }_{a}^{c} D_{t}^{m} f(t)\right)={ }_{a}^{c} D_{t}^{\alpha+m} f(t),(m=0,1,2, \ldots ; n-1<\alpha<n)
$$

Meanwhile:

$$
\begin{aligned}
& { }_{a}^{c} D_{t}^{\alpha}\left({ }_{a}^{c} D_{t}^{m} f(t)\right)={ }_{a}^{c} D_{t}^{m}\left({ }_{a}^{c} D_{t}^{\alpha} f(t)\right)={ }_{a}^{c} D_{t}^{\alpha+m} f(t) \\
& f^{(N)}(0)=0, N \in \mathbb{N}, N=n, n+1, \ldots, m \\
& (m=0,1,2, . . ; n-1<\alpha<n)
\end{aligned}
$$

In the following, the above fractional calculus is combined with the synergetic control theory to obtain appropriate control law.

\section{METHODOLOGY: ANALYTICAL INVESTIGATION OF THE STABILITY OF FRACTIONAL-ORDER MANIFOLD SYNERGETIC CONTROLLER}

In this section, the synergetic controller in Eqn.(2) to Eqn.(6) gains a fractional manifold. The combination gives advantages of both the synergetic theory and the fractional calculus. The latter provides more flexibility and degree of freedom to design the fractional controller. When a higher integer order is needed a small size fractional controller provides better results [17, 33-35]. The idea is also developed to consider a linear combination of state variables. In this regard, a fractional order form of the synergetic manifold of Eqn.(3) is proposed as follows:

$$
T \psi^{(\alpha)}+\psi^{(\alpha-1)}=0, \quad T>0
$$

where $\alpha$ is a real number in the interval $\alpha \in(0,1)$. In the following, performance of the proposed controller is compared with conventional synergetic controller of integer order manifold when fractional order chaotic Coullet system [36] is controlled. Chaotic systems are found very sensitive to initial conditions. This means two identical systems but with a minor deviation in their initial conditions may produce a completely different result. Hence, it is difficult predict the behavior of these systems. The term Chaos arises from a deterministic dynamic with nearly stochastic (almost unpredictable) behavior. The chaos effect and control is a more challenging topic. Therefore the following section addressess control of chaotic Coullet dynamic.

\subsection{Stabilizing the Chaos}

The Coullet system is used in a synchronization approach, which is as follows: 


$$
\left\{\begin{array}{c}
D^{\alpha} x_{1}=x_{2} \\
D^{\alpha} x_{2}=x_{3} \\
D^{\alpha} x_{3}=a x_{1}+b x_{2}+c x_{3}+d x_{1}^{3}
\end{array}\right.
$$

Parameters of the Coullet system are chosen as a $=0.8, \mathrm{~b}=-1.1, \mathrm{c}=-0.45, \mathrm{~d}=-1$ and $\alpha=$ 0.95 together with the state initial conditions: $\mathrm{x}_{1}(0)=-0.8, \mathrm{x}_{2}(0)=1.2$ and $\mathrm{x}_{3}(0)=0.2$. State response of the system (4.2) to initial conditions is simulated in 50 seconds where depicted in Fig. 1 for $x_{1}-x_{3}$. Fourth plot in Fig. 1 represents a phase portrait of the system.
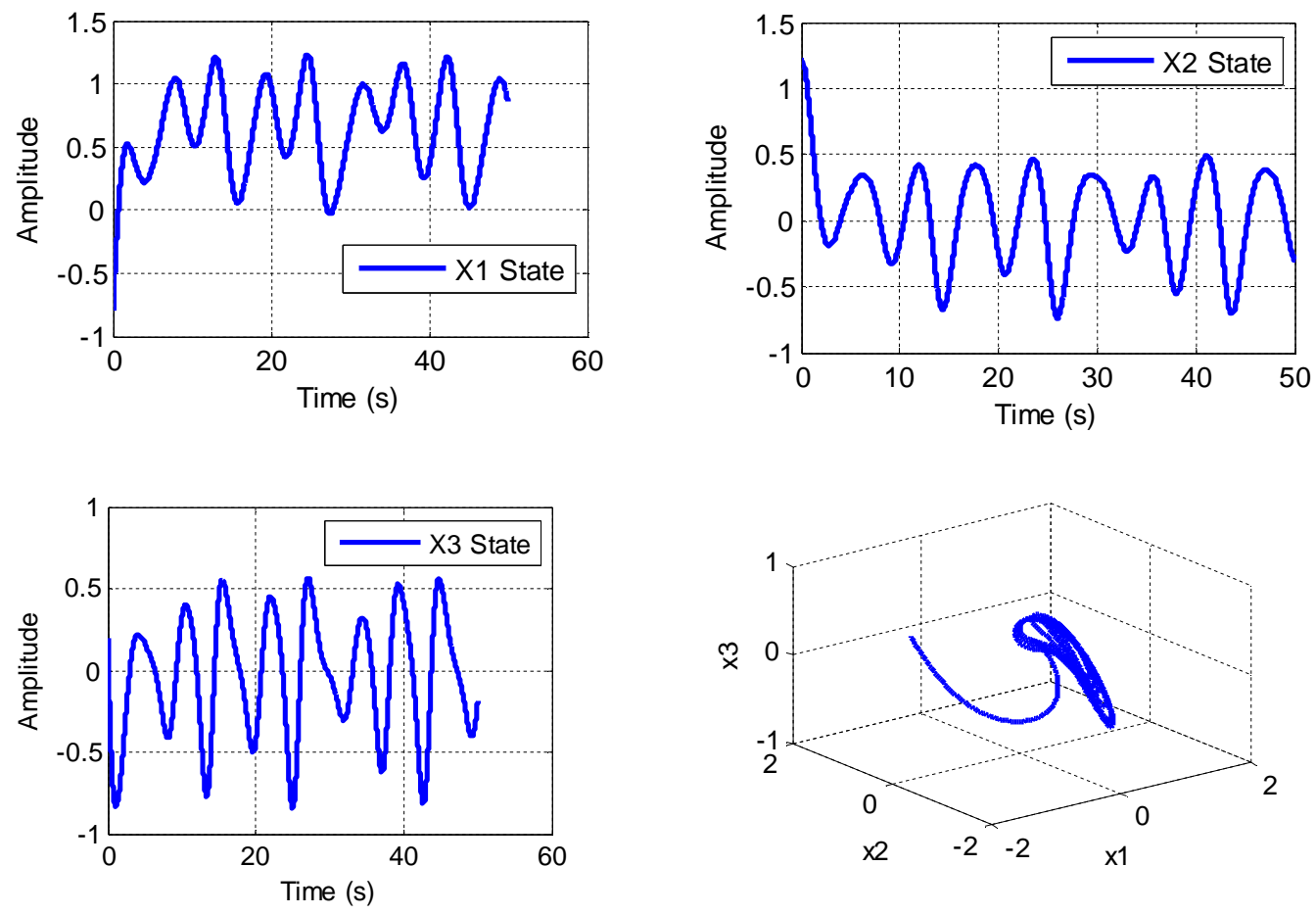

Fig. 1: States $\left(\mathrm{x}_{1}-\mathrm{x}_{3}\right)$ responses of together with a phase portrait (fourth).

As can be seen from the first three graphs in Fig. 1, state $\mathrm{x}_{1}-\mathrm{x}_{3}$ are of chaotic (neither periodic nor converging). The fourth plot also confirms states fail to converge to any point. To deeply verify the chaos, an FFT of $\mathrm{x}_{1}$ is assessed and plotted in Fig. 2, using power GUI facility in the MATLAB ${ }^{\mathrm{TM}}$ simulink.

As can be seen from Fig. 2, all of the frequency components occur in the frequency spectrum. This is in confirmation that the signal is not pure oscillatory. This is main characteristics of chaos (similar to frequency characteristics of noise) where all frequencies can be seen in the chaos [5-6, 37-38]. Although this is for $\mathrm{x}_{1}$, similar results are achieved for $\mathrm{x}_{2}$ and $\mathrm{x}_{3}$.

In order to control the chaos, a control effort $u(t)$ is applied to the third equation of Eqn.(4.2):

$$
\left\{\begin{array}{c}
D^{\alpha} x_{1}=x_{2} \\
D^{\alpha} x_{2}=x_{3} \\
D^{\alpha} x_{3}=a x_{1}+b x_{2}+c x_{3}+d x_{1}^{3}+u
\end{array}\right.
$$




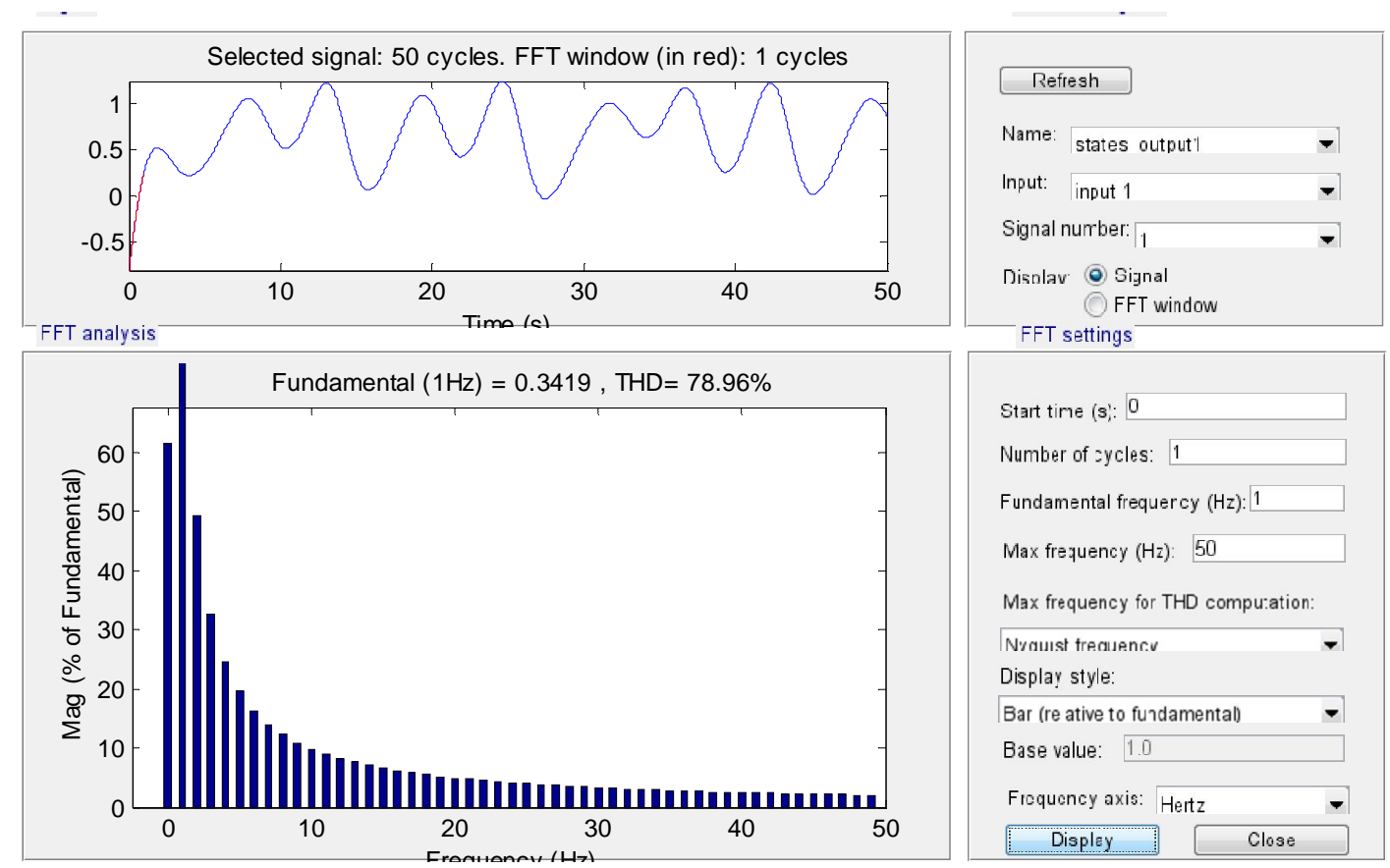

Fig. 2: Time (the above) and frequency (bottom) response of state $\mathrm{x}_{1}$ of the Coullet system.

The control takes places using the synergetic technique. The duty is to provide zero convergence of the state variables. The macro variable is defined as follows [2]:

$$
\psi=x_{1}+x_{2}+x_{3}
$$

In order to make more degree of freedom, arbitrary gains of $k_{1}, k_{2}$ and $k_{3}$ are innovatively added to the macro variable in Eqn. (16). This generalization expands the macro as in the following:

$$
\psi=k_{1} x_{1}+k_{2} x_{2}+k_{3} x_{3}
$$

It will be shown that the proposed macro in Eqn. (17) increases the performance. The required control effort can be obtained when the conventional manifold in Eqn. (16) i.e. $\psi=$ $\mathrm{x}_{1}+\mathrm{x}_{2}+\mathrm{x}_{3}=0$ is substituted into Eqn. (13), which is as follows:

$$
\begin{gathered}
u=-\frac{1}{T}\left\{T\left(x_{1}{ }^{(\alpha)}+x_{2}{ }^{(\alpha)}+\left(a x_{1}+b x_{2}+c x_{3}+d x_{1}^{3}\right)\right)\right. \\
\left.+\left(x_{1}{ }^{(\alpha-1)}+x_{2}{ }^{(\alpha-1)}+x_{3}{ }^{(\alpha-1)}\right)\right\}
\end{gathered}
$$

Likewise, anew control law is derived for the proposed manifold in Eqn. (17) using the following fractional dynamical equation of macro variables:

$$
T \psi^{(\alpha)}+\psi^{(\alpha-1)}=0, \quad T>0
$$

Substitution of Eqn. (19) into Eqn. (13) yields:

$$
T\left(k_{1} x_{1}^{(\alpha)}+k_{2} x_{2}^{(\alpha)}+k_{3} x_{3}^{(\alpha)}\right)+\left(k_{1} x_{1}^{(\alpha-1)}+k_{2} x_{2}^{(\alpha-1)}+k_{3} x_{3}^{(\alpha-1)}\right)=0
$$


where $x^{(\alpha)}$ is $\alpha$-order derivative of state variable $x$ in the Caputo sense as:

$$
x^{(\alpha)}=D^{\alpha} x=d^{\alpha} x / d t^{\alpha}
$$

By substituting dynamical equation Eqn. (15) into Eqn. (20), the following equation is obtained:

$$
\begin{aligned}
T\left(k_{1} x_{1}{ }^{(\alpha)}+\right. & \left.k_{2} x_{2}{ }^{(\alpha)}+k_{3}\left(a x_{1}+b x_{2}+c x_{3}+d x_{1}^{3}+u\right)\right) \\
+ & \left(k_{1} x_{1}^{(\alpha-1)}+k_{2} x_{2}^{(\alpha-1)}+k_{3} x_{3}^{(\alpha-1)}\right)=0
\end{aligned}
$$

The control input $u$ is finally extracted form (22) which is as follows

$$
\begin{aligned}
u=-\frac{1}{T k_{3}}\{T & \left(k_{1} x_{1}{ }^{(\alpha)}+k_{2} x_{2}{ }^{(\alpha)}+k_{3}\left(a x_{1}+b x_{2}+c x_{3}+d x_{1}^{3}\right)\right) \\
+ & \left.\left(k_{1} x_{1}^{(\alpha-1)}+k_{2} x_{2}^{(\alpha-1)}+k_{3} x_{3}^{(\alpha-1)}\right)\right\}
\end{aligned}
$$

The stability of the proposed controller will be analyzed through the following theorem:

Theorem: Consider the Coullet fractional order system in Eqn. (15). If the control law in Eqn. (23) is applied, system states asymptotically converge to zero.

Proof: The Lyapunov function is candidate as in the following:

$$
V=\frac{1}{2}\left(\psi^{(\alpha-1)}\right)^{2} \geq 0
$$

The conventional derivative yields:

$$
\dot{\mathrm{V}}=\left(\psi^{(\alpha-1)}\right)^{(1)} \psi^{(\alpha-1)}=\psi^{(\alpha)} \psi^{(\alpha-1)}
$$

A fractional form of the macro-variable i.e. $\psi^{(\alpha)}$, is achieved as follows:

$$
\begin{aligned}
\psi^{(\alpha)}=k_{1} x_{1}{ }^{(\alpha)} & +k_{2} x_{2}{ }^{(\alpha)}+k_{3} x_{3}{ }^{(\alpha)} \\
& =k_{1} x_{1}{ }^{(\alpha)}+k_{2} x_{2}{ }^{(\alpha)}+k_{3}\left(a x_{1}+b x_{2}+c x_{3}+d x_{1}^{3}+u\right)
\end{aligned}
$$

Replacement the control effort $u(t)$ from Eqn. (23) into Eqn. (26) provides:

$$
\begin{aligned}
\psi^{(\alpha)}=k_{1} x_{1}{ }^{(\alpha)} & +k_{2} x_{2}{ }^{(\alpha)}+k_{3}\left(a x_{1}+b x_{2}+c x_{3}+d x_{1}^{3}\right. \\
& -\frac{1}{T k_{3}}\left\{T\left(k_{1} x_{1}{ }^{(\alpha)}+k_{2} x_{2}{ }^{(\alpha)}+k_{3}\left(a x_{1}+b x_{2}+c x_{3}+d x_{1}^{3}\right)\right)\right. \\
& \left.+\left(k_{1} x_{1}{ }^{(\alpha-1)}+k_{2} x_{2}{ }^{(\alpha-1)}+k_{3} x_{3}^{(\alpha-1)}\right)\right\} \\
& =-\frac{1}{T}\left(k_{1} x_{1}{ }^{(\alpha-1)}+k_{2} x_{2}{ }^{(\alpha-1)}+k_{3} x_{3}^{(\alpha-1)}\right)=-\frac{1}{T} \psi^{(\alpha-1)}
\end{aligned}
$$

Substituting $\psi^{(\alpha)}=-\frac{1}{\mathrm{~T}} \psi^{(\alpha-1)}$ from Eqn. (27) into Eqn. (25) achieves: 


$$
\dot{\mathrm{V}}=-\frac{1}{T} \psi^{(\alpha-1)} \psi^{(\alpha-1)}=-\frac{1}{T}\left(\psi^{(\alpha-1)}\right)^{2} \leq 0
$$

Inequality Eqn. (28) guarantees strictly decreasing nature of the Lyapunov function in Eqn. (22). This confirms that the control input Eqn. (21) is a stabilizing control effort for system Eqn. (15).

\section{RESULTS: APPLICATION OF THE PROPOSED SYNERGETIC CONTROLLER TO CONTROL A CHAOS}

A simulation is carried out for the fractional order Coullet system gaining both the manifold in Eqn. (16) [2] and the proposed manifold in Eqn. (17). Time responses of three states are shown in Fig. 3, Fig. 4 and Fig. 5 when initial conditions are assumed as $x_{1}(0)=$ $-0.8, x_{2}(0)=1.2, x_{3}(0)=0.2$ and $\mathrm{T}=0.1$ whilst gains are chosen $k_{1}=3, k_{2}=5$ and $k_{3}=1$ using Eqn. (3) to Eqn. (6).

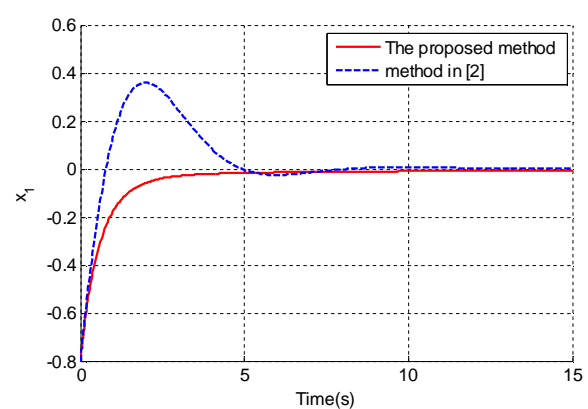

Fig. 3: Time response of state variable $\mathrm{x}_{1}$ in fractional order Coullet system with conventional macro Eqn. (16) as $\psi=$ $x_{1}+x_{2}+x_{3}=0$ and the proposed macro Eqn. (17) as $\psi=k_{1} x_{1}+k_{2} x_{2}+$ $k_{3} x_{3}=0$.

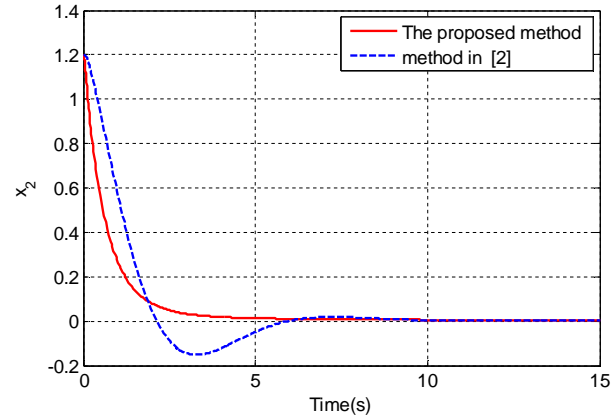

Fig. 4: Time response of state variable $\mathrm{x}_{2}$ in fractional order Coullet system with conventional macro Eqn. (16) as $\psi=x_{1}+$ $x_{2}+x_{3}=0$ and the proposed macro Eqn.

(17) as $\psi=k_{1} x_{1}+k_{2} x_{2}+k_{3} x_{3}=0$.

From Fig. 3 it can be seen that by considering extra gains into Eqn. (16) the macro variable in Eqn. (17) causes reduction in the overshoot. Meanwhile better performance with respect to the conventional macro variable in Eqn. (17) is also achieved. However, errors in two methods approach zero. The time behavior of the second state variable in Fig. 4 is similar to the first state variable as in Fig. 3. In contrast to those two state variables, the third state variable in Fig. 5 provides more negative peak with respect to that of the conventional macro in Eqn. (16). However, the proposed macro in Eqn. (17) provides a faster convergence rate (with the price of more negative peak). This necessitates to tune those gains in an optimal way rather than simple selection of $k_{1}=3, k_{2}=5$ and $k_{3}=1$. Fortunately, this probable draw back requires no more attention to provide the control effort which is depicted in Fig. 6 which makes the lack of negative peak negligible. 


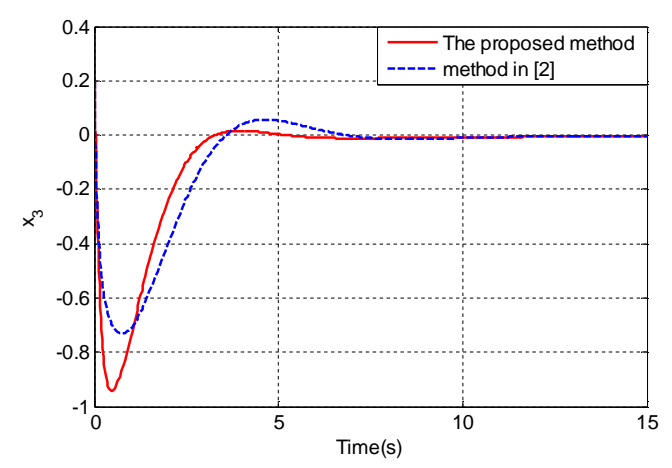

Fig. 5: Time response of state variable $\mathrm{x}_{3}$ in fractional order Coullet system with conventional macro Eqn. (16) as $\psi=x_{1}+x_{2}+$ $x_{3}=0$ and the proposed macro Eqn. (17) as $\psi=k_{1} x_{1}+k_{2} x_{2}+$ $k_{3} x_{3}=0$.

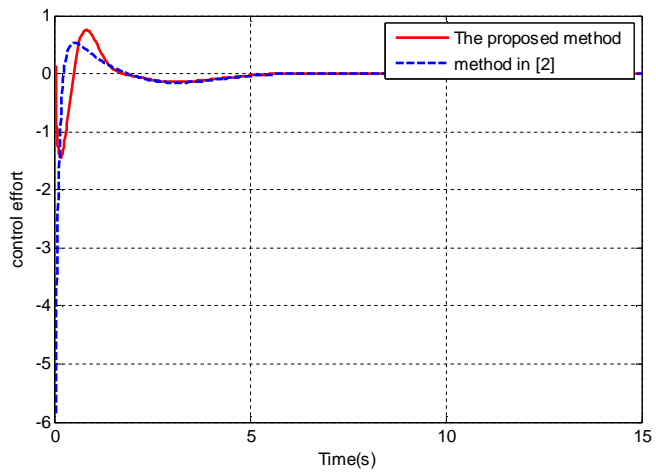

Fig. 6: The required control input for using the conventional macro in Eqn.

(16) as $\psi=x_{1}+x_{2}+x_{3}=0$ and the proposed macro Eqn. (17) as $\psi=$

$$
k_{1} x_{1}+k_{2} x_{2}+k_{3} x_{3}=0 \text {. }
$$

\section{SYNERGETIC SYNCHRONIZATION OF FRACTIONAL-ORDER COULLET SYSTEM}

Basically, chaos synchronization means forcing two systems work in a same way in a master-slave structure. The designed nonlinear control system obtains signals from the master to control the slave dynamics. Block diagram of the master and slave synchronization using the synergetic controller is shown in Fig. 7.

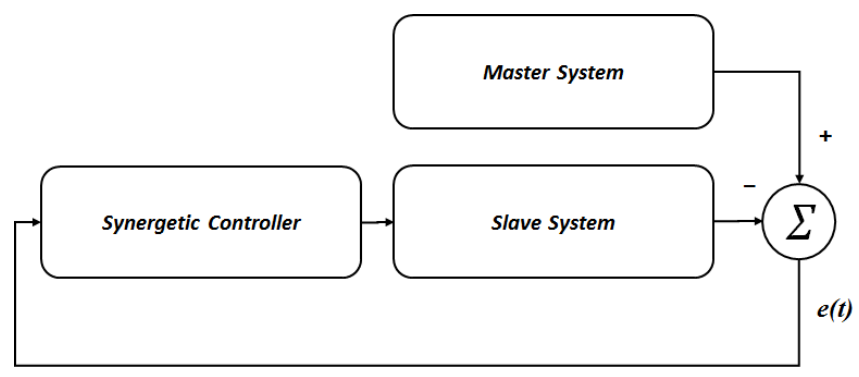

Fig. 7: Block diagram of the master and slave synchronization using the synergetic controller.

The goal is to synchronize a fractional-order Coullet system assuming the master as in Eqn. (29) to be followed by the slave as in Eqn. (5.2) using the proposed synergetic controller Eqn. (23).

$$
\left\{\begin{array}{c}
D^{\alpha} x_{1}=x_{2} \\
D^{\alpha} x_{2}=x_{3} \\
D^{\alpha} x_{3}=a x_{1}+b x_{2}+c x_{3}+d x_{1}^{3}
\end{array}\right.
$$

Supposing $x_{1}(0)=-0.8, \quad x_{2}(0)=1.2$ and $x_{3}(0)=0.2$ where the makes the system chaotic. The slave dynamics is similarly shown by: 


$$
\left\{\begin{array}{c}
D^{\alpha} y_{1}=y_{2} \\
D^{\alpha} y_{2}=y_{3} \\
D^{\alpha} y_{3}=a y_{1}+b y_{2}+c y_{3}+d y_{1}^{3}+u
\end{array}\right.
$$

Initial conditions of the slave are assumed different as $y_{1}(0)=1, y_{2}(0)=$ -1.2 and $y_{3}(0)=-0.4$. The error is defined as discrepancy of the corresponding states, i.e. $e_{\mathrm{i}}=y_{\mathrm{i}}-x_{\mathrm{i}}$ for $\mathrm{i}=1,2,3$. Deducing the master dynamic from the slave leads to:

$$
\left\{\begin{array}{c}
D^{\alpha} e_{1}=e_{2} \\
D^{\alpha} e_{2}=e_{3} \\
D^{\alpha} e_{3}=a e_{1}+b e_{2}+c e_{3}+d e_{1}^{3}+u
\end{array}\right.
$$

The same procedure as in Eqn. (19) to Eqn. (23) using the proposed linear gains leads to generate the following control effort:

$$
\begin{aligned}
& u=-\frac{1}{T k_{3}}\{ T\left(k_{1} e_{1}{ }^{(\alpha)}+k_{2} e_{2}{ }^{(\alpha)}+k_{3}\left(a e_{1}+b e_{2}+c e_{3}+d e_{1}^{3}\right)\right) \\
&\left.+\left(k_{1} e_{1}^{(\alpha-1)}+k_{2} e_{2}^{(\alpha-1)}+k_{3} e_{3}^{(\alpha-1)}\right)\right\}
\end{aligned}
$$

A proper selection of control parameters $k_{i}$, i.e. $k_{1}=3, k_{2}=5.75$ and $k_{3}=1$ provides $\lim _{t \rightarrow \infty} e_{i}$ $=0$. Outcomes of the synchronization are shown in Fig. 108, Fig. 9 and Fig. 10. The proof is similar to that of in Eqn. (24) to Eqn. (28). This immediately means that output of the slave asymptotically follows the master state i.e. $x_{\mathrm{i}}=y_{\mathrm{i}}$. This confirms that the synchronization between master and slave is made possible.
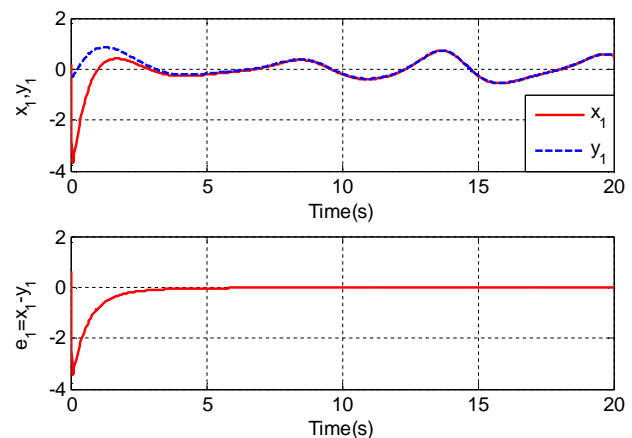

Fig. 8: Synchronization of states $x_{1}$ and $y_{1}$ together with the $e_{1}=x_{1}-y_{1}$.
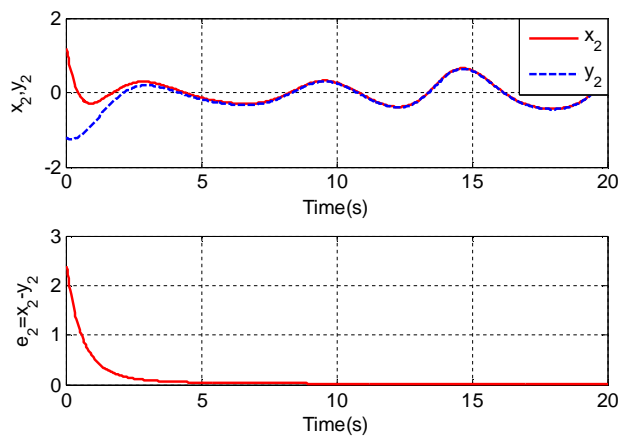

Fig. 9: Synchronization of states $x_{2}$ and $y_{2}$ together with the $e_{2}=x_{2}-y_{2}$.
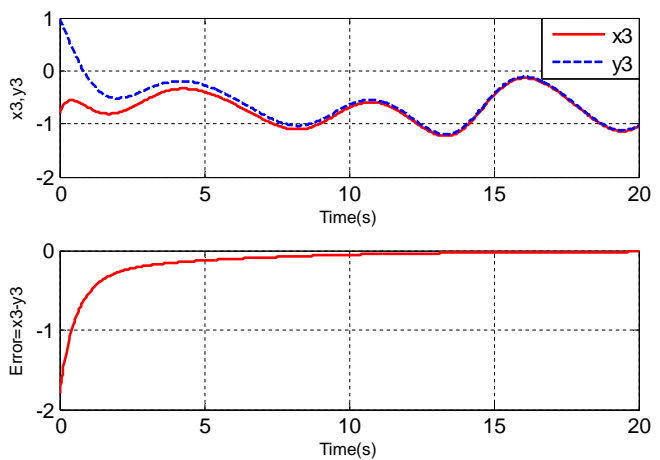

Fig. 10: Synchronization of states $x_{3}$ and $y_{3}$ together with the $e_{3}=x_{3}-y_{3}$. 


\section{DISCUSSION AND CONCLUSION}

In this paper, a new controller is proposed by considering a fractional derivative in linear weighted combination of state variables in the synergetic controller. The degree of freedom is also increased by adding control coefficients $k_{1}, k_{2}, k_{3}$ and $T$ to the designed synergetic manifold. By tuning parameters $k_{1}, k_{2}$ and $k_{3}$ frequency of oscillations is decreased when convergence is finally achieved. The stability of the proposed configuration is proven using the Lyapunov theory. The achievement confirms performance of the proposed structure. The parameters $k_{1}, k_{2}$ and $k_{3}$ are determined by a trial and error process, while they can be determined using intelligent algorithm such as PSO (Particle swarm optimization) or other algorithms to obtain better results.

\section{REFERENCES}

[1] Kolesnikov A, et al. (2000) Modern applied control theory: Synergetic approach in control theory. TRTU, Moscow, Taganrog.

[2] Djennoune S, Bettayeb M. (2013) Optimal synergetic control for fractional-order systems. Automatica, 49(7):2243-2249.

[3] Jiang Z. (2009) Design of a nonlinear power system stabilizer using synergetic control theory. Electric Power Sys. Res., 79(6):855-862.

[4] Jiang Z, Dougal RA. (2004) Synergetic control of power converters for pulse current charging of advanced batteries from a fuel cell power source. IEEE Trans. Power Electronic, 19(4):1140-1150.

[5] Santi E, et al. (2003) Synergetic control for DC-DC boost converter: implementation options.IEEETrans.Ind.App., 39(6):1803-1813. http://dx.doi.org/10.1109/TIA.2003.818967

[6] Ni J, et al. (2014) Variable speed synergetic control for chaotic oscillation in power system. Nonlinear Dynamics, 78(1):681-690.

[7] Delavari H, Lanusse P, Sabatier J. (2013) Fractional order controller design for a flexible link manipulator robot. Asian J. Control, 15(3):783-795.

[8] El-Khazali R. (2013) Fractional-order controller design. Computers \& Mathematics with Applications, 66(5):639-646.

[9] Faieghi MR, Delavari H, Baleanu D. (2012) Control of an uncertain fractional-order Liu system via fuzzy fractional-order sliding mode control. J. Vib. Control, 18(9), 1366-1374.

[10] Kilbas AAA, Srivastava HM, Trujillo JJ. (2006) Theory and applications of fractional differential equations, vol. 204, Elsevier Science Limited.

[11] Magin RL. (2006) Fractional calculus in bioengineering. Begell House, Rodding.

[12] Mainardi F. (1997) Fractional calculus. Springer.

[13] Monje, CA, et al. (2010) Fractional-order systems and controls: fundamentals and applications. Springer.

[14] Odibat Z, Momani S. (2006) Application of variational iteration method to nonlinear differential equations of fractional order. Int. J. Nonlinear Sci. Num. Simulation, 7(1):27-34.

[15] Podlubny I. (1998) Fractional differential equations: an introduction to fractional derivatives, fractional differential equations, to methods of their solution and some of their applications. vol. 198. Academic press.

[16] Sabatier J, Agrawal OP, Machado JT. (2007) Advances in fractional calculus. Springer.

[17] Luo Y, et al. (2010) Tuning fractional order proportional integral controllers for fractional order systems. J. Process Control, 20(7):823-831.

[18] Meng L, Wang DF, Han P. (2012) Identification of fractional order system using particle swarm optimization. IEEE International Conference on Machine Learning and Cybernetics (ICMLC).

[19] Saxena R, Mathai A, Haubold H. (2004) Unified fractional kinetic equation and a fractional diffusion equation. Astrophysics and Space Science, 290(3-4):299-310.

[20] Bagley RL, Torvik P. (1983) A theoretical basis for the application of fractional calculus to viscoelasticity. J. Rheology, 27(3):201-210. 
[21] Di Paola M, Zingales M. (2012) Exact mechanical models of fractional hereditary materials. J. Rheology, 56(5):983-1004.

[22] Hilfer R, et al. (2000) Applications of fractional calculus in physics. vol. 128. World Scientific.

[23] Poinot T, Trigeassou J. (2004) Identification of fractional systems using an output-error technique. Nonlinear Dynamics, 38,133-154.

[24] Cois O, Oustaloup A, Battaglia E. (2000) Non-integer model from modal decomposition for time domain system identification. 12th IFAC Symposium on System Identification, Santa Barbara, CA, USA.

[25] Sabatier J, et al. (2002) CRONE control: Principles and extension to time-variant plants with asymptotically constant coefficients. Nonlinear Dynamics, 29(1-4):363-385.

[26] Podlubny I. (1999) Fractional-order systems and PI/sup/spl lambda//D/sup/spl mu//controllers. IEEE Trans. Autom. Control, 44(1):208-214.

[27] Nechadi E, et al. (2012) Type-2 fuzzy based adaptive synergetic power system control. Electric Power Sys. Res., 88:9-15.

[28] Santi E, et al. (2004) Synergetic control for power electronics applications: a comparison with the sliding mode approach. J. Circ. Sys. Comp., 13(4):737-760.

[29] Caputo M. (1969) Elasticita' e dissipazione. Zanichelli. Bologna.

[30] Caputo M. (1989) The rheology of an anelastic medium studied by means of the observation of the splitting of its eigenfrequencies. J. Acoustical Soc. America, 86(5):1984-1987.

[31] El-Sayed AM. (1995) Fractional order evolution equations. J. Fract. Calc, 7:89-100.

[32] El-Sayed AM, Ibrahim A. (1995) Multivalued fractional differential equations. App. Math. Comp., 68(1):15-25.

[33] Vinagre B, et al. (2002) Using fractional order adjustment rules and fractional order reference models in model-reference adaptive control. Nonlinear Dynamics, 29(1-4):269-279.

[34] Xue D, Zhao C, Chen Y. (2006) Fractional order PID control of a DC-motor with elastic shaft: a case study. Proceedings of American Control Conference.

[35] Jesus IS, Machado JT. (2008) Fractional control of heat diffusion systems. Nonlinear Dynamics, 54(3):263-282.

[36] Arneodo A, Coullet P, Tresser C. (1981) Possible new strange attractors with spiral structure. Comm. Math. Phys., 79(4):573-579.

[37] Liu Y, Chen L. (2013) Chaos in attitude dynamics of spacecraft. Springer.

[38] Petržela J, Kolka Z, Hanus S. (2011) Simple chaotic oscillator: from mathematical model to practical experiment. Models and Applications of Chaos Theory in Modern Sciences, p. 317. 